\title{
Physiological and biochemical response to higher temperature stress in hot pepper (Capsicum annuum L.)
}

\author{
Navita Ghai $^{1}$, Jaspreet Kaur ${ }^{1}$, S K Jindal ${ }^{2}$, M.S. Dhaliwal ${ }^{2}$ and Kanchan Pahwa ${ }^{1}$ \\ ${ }^{1}$ Department of Botany, Punjab Agricultural University, Ludhiana -141001 (Punjab), INDIA \\ 2 Department of Vegetable Science, Punjab Agricultural University, Ludhiana -141001 (Punjab), INDIA \\ *Corresponding author: E-mail. brar.brar29@ymail.com
}

Received: July 10, 2015; Revised received: April 11, 2016; Accepted: July 1, 2016

\begin{abstract}
The present study was conducted to evaluate the physiological and biochemical changes in some thermotolerant and thermosensitive chilli (Capsicum annuum L.) genotypes. Fourteen chilli genotypes (SL 461, PP 404, DL 161, MS 341, VR 521, PB 405, PS 403, SD 463, FL 201, AC 102, S 343, SL 462 and SL 464 along with sensitive check [Royal Wonder of bell pepper] were evaluated for heat tolerance. The observations on morpho-physiological and biochemical parameters were recorded at 45, 65, 85 and 105 days after transplanting (DAT) (high temperature period). On the basis of our studies, genotypes S 343, AC 102 and FL 201 were found to be relatively thermotolerant. However, high temperature markedly decreased the photosynthetic activity of chilli plants by decreasing the photosynthetic pigments in leaf chloroplasts of all the genotypes. The levels of ascorbic acid, total soluble sugars and total phenols increased in the leaves of all the genotypes with the maturity of the crop. Electrolyte leakage and proline content also increased with rise in temperature. Genotypes AC 102 and S 343 were able to accumulate the maximum ascorbic acid, proline, total soluble sugars and total phenols under heat stress conditions. Decrease in fruit set percent led to reduction in the total yield per plant. Maximum yield was observed in genotype $S 343$ followed by FL 201.
\end{abstract}

Keywords: Chilli, High Temperature, Photosynthetic activity, Proline

\section{INTRODUCTION}

Hot pepper (Capsicum annuum L.) is an important commercial vegetable crop grown in India, both for fresh market and processing industry. It is heavily consumed throughout the world and valued for its colourants, flavors, and pungency principles (Conforti et al., 2007). It is a rich source of Vitamin C, A and B. High temperature stress is one of the major limiting factors for chilli production. High temperature induces the abscission of flower buds, flowers and young fruits which is the limiting factor for the chilli production (AVRDC, 2003). In chilli, flower abscission is high if day temperature is in the range of $32-38^{\circ} \mathrm{C}$, whereas fruit retention is maximal at $16-21^{\circ} \mathrm{C}$ day temperature. Heat stress effects are notable at various levels, including plasma membrane and biochemical pathways operative in the cytosol or cytoplasmic organelles (Sung et al., 2003). Plants implement various mechanisms including maintenance of membrane stability, scavenging of reactive oxygen species (ROS), production of antioxidants, accumulation and adjustment of compatible solutes in order to cope with heat stress. The adverse effects of heat stress can be mitigated by developing crop cultivars with improved thermotolerance. For this purpose, a thorough understanding of physiological and biochemical responses of plants to high temperature, mechanism of heat tolerance and possible strategies for improving thermotolerance is important. Identification of chilli genotypes tolerant to high temperature will pave the way for the development of crop cultivars tolerant to heat stress, stabilize crop production and extend the availability period of good quality fruits.

\section{MATERIALS AND METHODS}

Physiological and biochemical parameters: Fourteen genotypes of Capsicum annuum L. viz., SL 461, PP 404, DL 161, MS 341, VR 521, PB 405, PS 403, SD 463, FL 201, AC 102, S 343, SL 462 and SL 464 along with sensitive check [Royal Wonder of bell pepper] were raised in a nursery during 2012-13. All the required field management practices were followed according to the specifications given in the Package of Practices for Vegetable Crops, Punjab Agricultural University, Ludhiana (Anonymous, 2012). The genotypes were grown in randomized block design with three replications. There were 10 plants per treatment per replication and observations were recorded from 5 representative plants. Data on various observations were recorded at 10 day intervals after the initiation of flowering. Third leaf from the top was excised from the randomly taken plants with the help of blade and washed with distilled water for the estimation of various physiological and biochemical parameters. Elec- 
trolyte leakage of leaves was estimated by the method given by Fletcher and Drexlure (1980) and the method given by Anderson and Boardman (1964) was used to estimate total chlorophyll and carotenoid content.

The biochemical constituents estimated included ascorbic acid (Roe and Oesterling, 1943), total phenols (Swain and Hills, 1959), proline (Bates et al., 1973) and total soluble sugars (Dubois et al., 1956). For fruit set percent the fruits of each genotype were harvested which were tagged at an interval of ten days and the percentage of these harvested fruits was calculated.

Statistical Analysis: The data was statistically analyzed using CPCSI software and correlation analysis was carried out using MVM software.

\section{RESULTS AND DISCUSSION}

The metrological data pertaining to temperature and relative humidity according to Standard Metrological Weeks for Ludhiana (Punjab, India) during the study period is presented in Table 1 .

Physiological and biochemical parameters: During the present investigation, it was observed that cellular membranes in all the genotypes lost their permeability with increasing temperature (Table 2). Continuous increase in cell membrane damage was observed from 45 DAT to 85 DAT followed by an increase in membrane stability at 105 DAT. The cellular membrane of

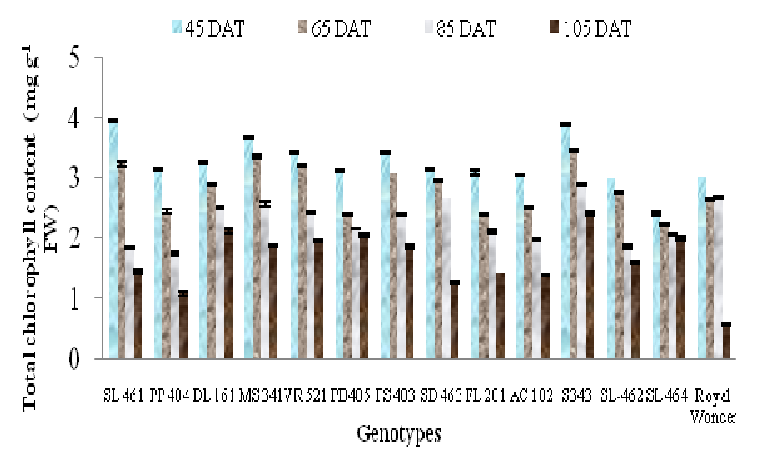

Fig. 1. Effect of heat stress on total chlorophyll content ( $\mathrm{mg}$ $\left.g^{-1} F W\right)$ in different chilli genotypes

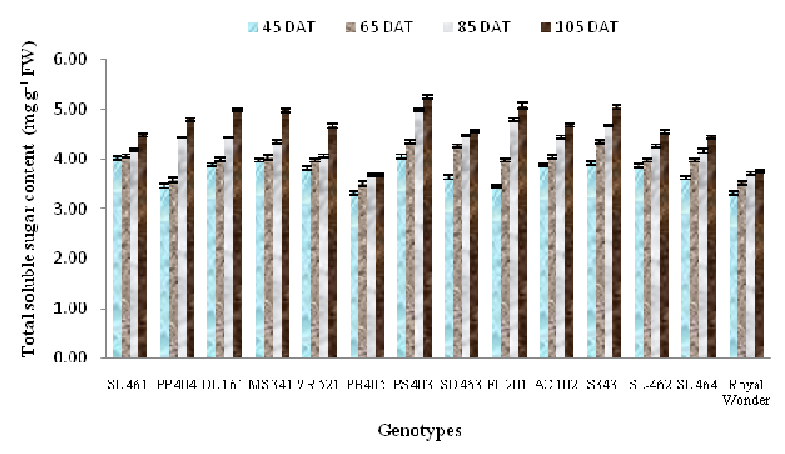

Fig. 3. Effect of heat stress on proline content ( $\left.\mathrm{mg}^{-1} \mathrm{FW}\right)$ in different chilli genotypes. cv. Royal Wonder proved to be most stable even at high temperature, although it is considered to be a sensitive variety. However with increase in temperature its membrane also showed loss of permeability $(57.5 \%$ electrolyte leakage at $35.6^{\circ} \mathrm{C}$ as compared to $32.6 \%$ at $27.4^{\circ} \mathrm{C}$. The genotype MS 341 showed maximum increase in electrolyte leakage with increasing temperature. At 85 DAT $\left(35.6^{\circ} \mathrm{C}\right)$ maximum electrolyte leakage was observed in S $343(97.45 \%)$ followed by AC $102(94.63 \%)$ and SL 461 (94.28\%) in comparison to cv. Royal Wonder where electrolyte leakage was $57.5 \%$ at this temperature. However, the cellular membrane of all the genotypes showed stability at 105 DAT. High temperatures is known to cause membrane disruption and hence increase in electrolyte leakage. A decrease in temperature and increase in relative humidity at 105 DAT might be responsible for imparting stability to cellular membranes at these stages. Heat stress induced increase in electrolyte leakage has also been reported by Gulen and Eris (2004) in strawberry, Sohan and Back (2007) in rice, Almesalmani et al (2009) in wheat and Kumar et al (2011) in mungbean seedlings.

The ascorbic acid and total phenols content in leaf tissues increased in all the genotypes with maturity of the crop (Table 2). At 45 DAT, leaves of genotype FL 201 exhibited maximum ascorbic acid while at 105 DAT the genotype S 343 showed maximum content (4.34

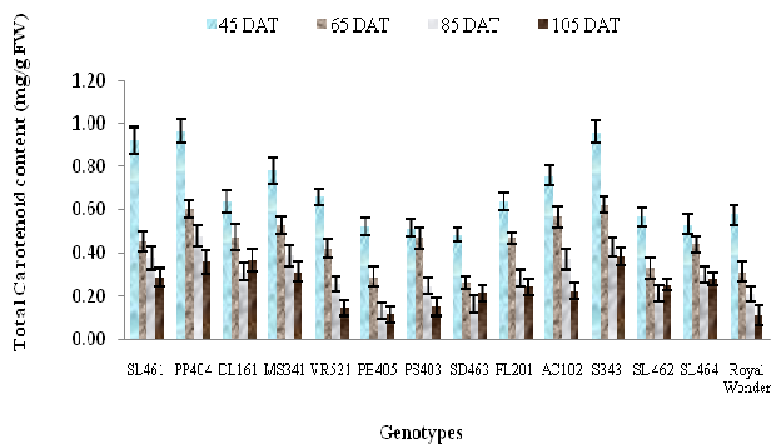

Fig. 2. Effect of heat stress on total carotenoid content ( $m g$ g ${ }^{I} \mathrm{FW}$ ) in different chilli genotypes.

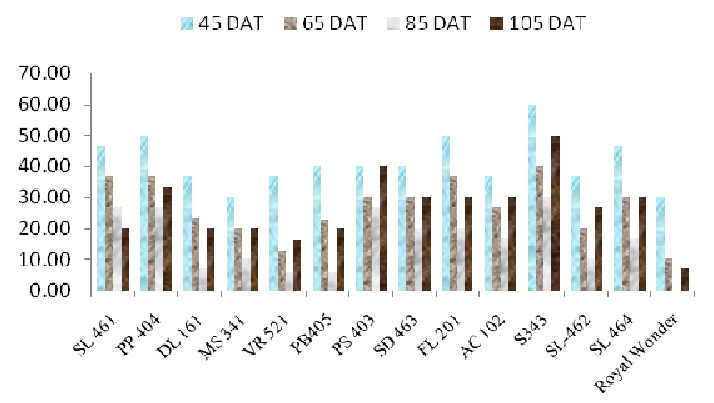

Fig. 4. Effect of heat stress on total soluble sugar ( $\mathrm{mg}^{-1}$ $F W)$ in different chilli genotypes. 


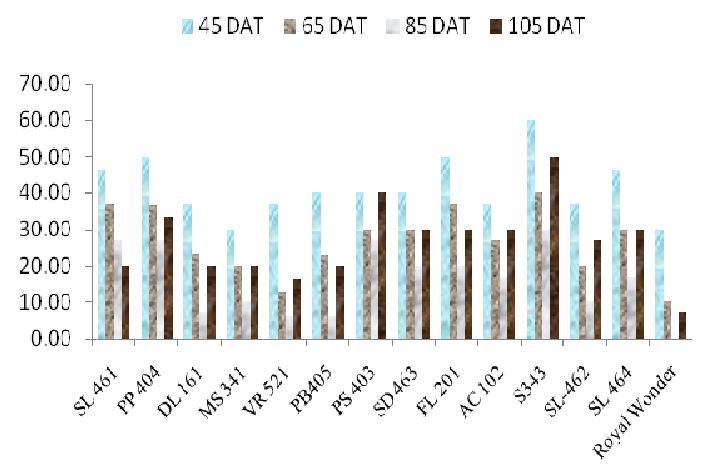

Fig. 5. Effect of heat stress on fruit set percent (\%) in different chilli genotypes.

$\mathrm{mg} \mathrm{g}^{-1} \mathrm{FW}$ ) and it was at par with that in AC 102 (4.12 $\left.\mathrm{mg} \mathrm{g}^{-1} \mathrm{FW}\right)$. The least content was exhibited by the sensitive check cv. Royal Wonder $\left(1.25 \mathrm{mg} \mathrm{g}^{-1}\right.$ $\mathrm{FW})$. At $85 \mathrm{DAT}$, also when temperature was the highest, AC 102 exhibited maximum ascorbic acid content followed by S 343 and it was significantly higher than all other genotypes. Qin et al (2009) also reported an increase in leaf ascorbic acid content of potato plants under high temperature conditions. Ascorbic acid is postulated to maintain the stability of plant cell membranes against oxidative damage by scavenging cytotoxic free radicals. Maximum phenol content was exhibited by genotype S 343 at all the stages of development and least was shown by PB 405 . However, at 105 DAT, the sensitive check variety Royal Wonder showed least phenol content followed by SD 463 and PB 405. At 105 DAT, all the genotypes showed significantly higher phenol content than the check cV. Royal Wonder at 105 DAT. Thermal stress induces the production of phenolic compounds in plants (Rivero et al., 2001). Enhanced synthesis of secondary metabolites under heat stress conditions protects plant against oxidative damage.

The total chlorophyll and carotenoid content in leaf tissues showed a decreasing trend with the maturity of the crop (Fig. 1 and 2). During the period of investigation, genotype S 343 showed maximum mean chlorophyll content, followed by MS 341 and VR 521 (Fig. 1). However at 45 DAT, genotype SL 461 exhibited maximum chlorophyll content followed by $S 343$ while SL 464 showed minimum chlorophyll content. At 105 DAT, S 343 showed maximum total chlorophyll content and it was significantly more than all other genotypes. The sensitive check cv. Royal Wonder showed maximum degradation of chlorophyll and its content was the least in comparison to all other genotypes at 105 DAT. Loss of chlorophyll due to high temperature has also been reported in tomato (Camejo and Torres,2001) and other crops (Kumar et al., 2011). The mechanism by which high temperature may have caused chlorophyll loss is, however unclear. But it might be a consequence of heat induced damage to thylakoid membrane and oxygen evolving complex of PS II (Komayama et al., 2007). Earlier Cornic (2000) had suggested that degradation of chlorophyll in stressed leaves is due to activity of enzyme chlorophylase. At all the stages maximum carotenoid content (Fig. 2) was shown by S 343 and PP 404 while minimum was exhibited by SD 463 at most of the developmental stages. However, at 105 DAT Royal wonder showed minimum carotenoid content and it was significantly lower than all other genotypes studied. Carotenoids are known to absorb wavelength that chlorophyll can't absorb and transfer it to central reaction in photosystem II. These are widely known to protect cellular structures in various plant species irrespective of the stress type (Wahid, 2007).

Proline content and total soluble sugars content increased continuously from 45 to 85 DAT in leaves of all the chilli genotypes evaluated and declined thereafter at 105 DAT (Fig. 3 and 4). At 85 DAT, maximum proline content was exhibited by S 343, which was $34.94 \%$ higher than check variety Royal Wonder followed by AC 10 and VR 521 (both showed 33.65\% increase in proline content as compared to variety Royal Wonder (Fig. 3). Minimum proline content was record in Royal Wonder (3.12 $\left.\mathrm{mg} \mathrm{g}^{-1} \mathrm{FW}\right)$. Proline is found to increase in response to high temperature stress as is evident from our data. The decline in proline content at 105 DAT could be attributed to lowering of temperature at these stages. Proline is considered to be a useful component for evaluating the tolerance of a crop to high temperature. Increase in proline content of leaves in pepper plants exposed to high temperature has also been reported by Saha et al. (2010). Genotype PS 403 recorded maximum total soluble sugar content at all the stages of development (Fig 4). The sugars content in S 343 was almost at par with PS 403 during early stages, however at 105 DAT, PS 403 recorded significantly more sugar content than S 343 . Leaves of genotype FL 201 also showed high total soluble sugars content. Although PB 405 recorded low least total soluble sugars content, the check variety Royal Wonder had slightly more sugar content than PB 405. At highest temperature during the study, i.e. at 85 DAT maximum total soluble sugars content was recorded in PS 403 followed by FL 201 and S 343. The sugars act as osmolytes, thereby protecting the plant from various types of stresses and also give an estimate of the assimilate available during that period (Wani et al., 2013). Total soluble sugars accumulation represents an adaptive response that could contribute to growth maintenance of plants under heat stress.

In our studies, maximum fruit set percent (Fig. 5) was observed in S $343\left(60 \%\right.$ at $27.4^{\circ} \mathrm{C}$ and $30 \%$ at $\left.35.6^{\circ} \mathrm{C}\right)$ at all stages, followed by PP $404\left(50 \%\right.$ at $27.4^{\circ} \mathrm{C}$ and $27 \%$ at $\left.35.6^{\circ} \mathrm{C}\right)$, FL $201\left(50 \%\right.$ at $27.4^{\circ} \mathrm{C}$ and $20 \%$ at $\left.35.6^{\circ} \mathrm{C}\right)$ and SL $461\left(46.66 \%\right.$ at $27.4^{\circ} \mathrm{C}$ and $27 \%$ at 
Table 1. Metrological data pertaining to temperature and relative humidity according to Standard Metrological Weeks during the study period (2013).

\begin{tabular}{lcccccc}
\hline \multirow{2}{*}{$\begin{array}{l}\text { Age of } \\
\text { trans- } \\
\text { plant }\end{array}$} & \multicolumn{3}{c}{ Temperature $\left({ }^{\circ} \mathbf{C}\right)$} & \multicolumn{3}{c}{ Relative humidity $(\%)$} \\
\cline { 2 - 7 } & $\begin{array}{c}\text { Ma } \\
\mathbf{x} .\end{array}$ & Min & $\begin{array}{c}\text { Mea } \\
\text { n }\end{array}$ & $\begin{array}{c}\text { Mor } \\
\text { n }\end{array}$ & Even. & $\begin{array}{c}\text { Mea } \\
\mathbf{n}\end{array}$ \\
\hline 45 DAT & 34.4 & 20.2 & 27.4 & 57 & 29 & 43 \\
55 DAT & 37.5 & 21.2 & 29.3 & 54 & 30 & 42 \\
65 DAT & 41.4 & 23.2 & 32.3 & 51 & 26 & 38 \\
75 DAT & 40.3 & 26.1 & 33.2 & 60 & 41 & 50 \\
85 DAT & 42.1 & 29.1 & 35.6 & 69 & 35 & 52 \\
95 DAT & 37.8 & 27.6 & 32.7 & 76 & 47 & 59 \\
105 DAT & 34.7 & 27.1 & 30.7 & 80 & 60 & 71 \\
\hline
\end{tabular}

$\left.35.6^{\circ} \mathrm{C}\right)$. The fruit set percent decreased with increasing temperature in all the genotypes along with check cv. Royal Wonder. At 105 DAT, maximum fruit set percent was shown by S 343 (50\%) followed by PS 403 (40\%), SL 461 (36.66) and PP 404 (33.3\%). The increased fruit set percent at 105 DAT could be attributed to decreased temperature and increased relative humidity at this stage ( Temperature $=30.7$ and $\mathrm{RH}=$ $71 \%$ ). Although the temperature was still on higher side but increased relative humidity played an important role in increasing fruit set percent in all the genotypes. The check variety Royal Wonder was most affected as it showed least fruit set percent at all the stages during high temperature. Notably this variety did not show any fruit set at $35.6^{\circ} \mathrm{C}$ (85 DAT). At this stage maximum fruit set was observed in S 343 (30\%) followed by SL 461, PP 404 and PS 403, all of which showed $27 \%$ fruit set. Inhibition of fruit set at high temperature is primarily due to abscission of mature flowers. High temperature directly affects pollen development. Abdulmalik et al. (2012) stated that the apparent reduction in fruit yield of sweet pepper could be attributed to restricted fruit set caused by dehydration and reduced assimilate partitioning. Dahal et al (2006) reported that under high temperature, long drought period and blowing of hot wind during flowering and fruiting period severely affected the fruit set and fruit size in chilli.

In conclusion, genotypes S 343, AC 102 and FL 201 could be considered as relative thermotolerant as compared to sensitive check variety Royal Wonder. Heat tolerance is a multigenic character, numerous biochemical and metabolic traits are also involved in the development and maintenance of thermotolerance: antioxidant activity, membrane lipid unsaturation, gene expression and translation, protein stability, and accumulation of compatible solutes (Kaya et al., 2001). Nevertheless, plant responses to high temperatures clearly depend on genotypic parameters, as certain

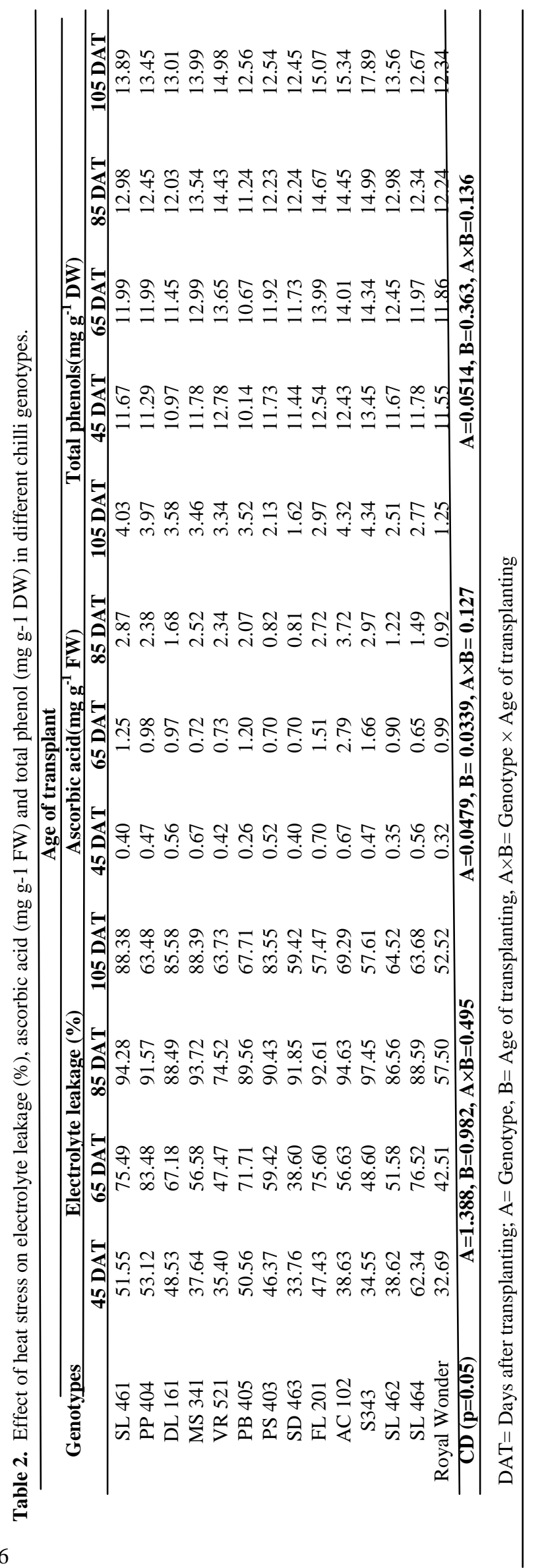


genotypes are more tolerant (Challinor et al., 2007). As photosynthesis and reproductive development are the most sensitive physiological processes to stress (Prasad et al., 2008), a heat-tolerant variety will be usually characterized by higher photosynthetic rates reflected in stay-green leaves, increased membranethermostability and successful fruit set under high temperature conditions (Scafaro et al., 2010).

\section{REFERENCES}

Abdulmalik, M. M., Olarewaju. J. D., Usman. I. S., and Ibrahim. A. (2012). Effects of moisture stress on flowering and fruit set in sweet pepper (Capsicum annuum L.) cultivars. PAT., 8(1): 191-98.

Almesalmani, M., Deshmukh, P. S. and Sairam. R. (2009) High temperature stress tolerance in wheat genotypes: role of antioxidants defence enzyme. Acta Agron Hung., 57: 1-14.

Anderson, J. M. and Boardman, N. K. (1964). Studies on greening of dark brown bean plants: development of phytochemical activity. Aus J Bio., 17: 93-101.

Anonymous. (2012). Package of practices for vegetable crops, Punjab Agricultural University, Ludhiana, Punjab. PP

AVRDC (2003) Development of high yielding, diseaseresistant chilli peppers. In: AVRDC Progress report 2003. Asian Vegetable Research and Development Centre, Shanhua, Taiwan. pp. 41-46.

Bates, L. S. Waldeen, R. P. O. and Teare, I. D. (1973). Rapid determination of free proline in water stress studies. Plant Soil., 39: 205-07.

Camejo, D. and Torres, W. (2001). High temperature effects on tomato (Lycopericon esculetinum) pigment and protein content and cellular viability. Cultivos Trop., 22: 13-17.

Challinor, A., Wheeler, T. Craufurd, P. Ferro, C. and Stephenson, D. (2007). Adaptation of crops to climate change through genotypic response to mean and extreme temperatures. Agric Ecosyst Environ., 119-190.

Conforti, F., Statti, G. A., and Menichini, F. (2007). Chemical and biological variability of hot pepper fruit (Capsicum annuum var. acuminatum) in relation to maturity stage. Food Chemis., 102: 1096-1104.

Cornic, G. (2000). Drought stress inhibits photosynthesis by decreased stomatal aperture not by affecting ATP synthesis. Trends Pl Sci., 5: 187-88.

Dahal, K. C., Sharma, M. D., Dhakal, D. D., and Shakya, S. M., (2006). Evaluation of heat tolerant chilli (Capsicum annuum L.) genotypes in western terai of Nepal. J Inst Agric Anim Sci., 27: 59-64.

Dubois, M., Gilles, K. A., Hamilton, J. K., Roberts, P. A., and Smith, F., (1956). Colorimetric method for the determination of sugars and related substances. Anal Chem., 28: 352-56.

Fletcher, R. A. and Drexlure, D. M. (1980). Interactions of dichloromethyl and 2, 4-D in cultivated oats (Avena sativa). Weed Sci., 28: 363-66.

Gulen, H. and Eris, A. (2004) Effect of heat stress on peroxi- dase activity and total protein content in strawberry plants. Plant Sci., 166: 739-44.

Kaya, H., Shibahara, K., Taoka, K., Iwabuchi, M., Stillman, B. and Araki, T. (2001). FASCIATA genes for chromatin assembly factor-1 in Arabdopsis maintain the cellular organization of apical meristems. Cell., 104-131.

Komayama, K., Khatoon, M., Takenaka, D., Horie, J., Yamashita, A., Yoshioka, M., Nakayama, Y., Yoshida, M., Ohira, S., Morita, N., Velitchkova, M., Enami, I. and Yamamoto, Y. (2007). Quality control of photosystem II: cleavage and aggregation of heat-damaged D1 protein in spinach thylakoids. Biochem Biophys Acta., 1767: 838-46.

Kumar, S., Kaur, R., Kaur, N., Bhandhari, K., Kaushal, N., Gupta, K., Bains, T. S. and Nayyar, H. (2011). Heat stress induced inhibition in growth and chlorosis in mungbean (Phaseolus aureus) is partly mitigated by ascorbic acid application and related to reduction in oxidative stress. Acta Physiol Plant., 33: 2091-2101.

Prasad, P., Pisipati, S., Mutava, R. and Tuinstra, M. 2008. Sensitivity of grain sorgum to high temperature stress during reproductive development. Crop Sci., 48: 1911-17.

Qin, A. G., Gao, J. J. and Yu, X, C. (2009). Effects of high - and low temperature stresses on ascorbic acid metabolism system in potato leaves. J Appl Eco., 20(12): 2964-70.

Rivero, R. M., Ruiz, J. M., Garcia, P. C., Lopez Lefebre, L. R., Sanchez, E. and Romero, L. (2001). Resistance to cold and heat stress: accumulation of phenolic compounds in tomato and watermelon plants. Plant Sci., 160: 315-31.

Roe, J. H. and Oesterling, M. J. 1943. The determination of dehydroascorbic acid and ascorbic acid in plant tissue by the 2, 4 dinitrophenyl hydrazine method. J Biol Chem., 152: 511-17.

Saha, S. R, Hossain, M. M., Rahman, M. M., Kuo, C. G. and Abdullah, S. (2010). Effect of high temperature stress on the performance of twelve sweet pepper genotypes. $J$ Agril Res., 35(3): 525-34.

Scafaro, A. P., Haynes, P. A. and Atwell, B. J. (2010). Physiological and molecular changes in Oryza meridionalis $\mathrm{Ng}$. a heat tolerant spices of wild rice. $J$ Exp Bot., 61: 191-202.

Sohan, S. O. and Back, K. (2007) transgenic rice tolerant to high temperature with elevated contents of dienoic fatty acids. Biol plant 51: 340-42.

Sung D Y, Kaplan F, Lee K J and Guy C L (2003) Acquired tolerance to temperature extremes. Trends Plant Sci., 8: 179-87.

Swain, T. and Hillis, W. E. 1959. The phenolic constituents of Prunus domestica-The qualitative analysis of phenolic constituents. J Sci Fd Agric., 10: 63-68.

Wahid, A., Gelani, S., Ashraf, M., and Foolad, M. R. (2007). Heat tolerance in plants: An overview. Environ Exp Bot., 61: 199-223.

Wani, S. H., Singh, N. B., Haribhushan, A. and Mir, J. I. (2013). Compatible solute engineering in plants for abiotic stress tolerance-role of glycine betain. Curr Genomics., 14(3) $157-65$. 